International Journal of Social Science And Human Research

ISSN(print): 2644-0679, ISSN(online): 2644-0695

Volume 03 Issue 09 September 2020

DOI: $10.47191 / \mathrm{ijsshr} / \mathrm{v3-i9-06}$

Page No.- $164-179$

\title{
Influence of Fishing Activities on HIV and AIDS Pandemic in Mfangano Island, Kenya
}

\author{
Michael Ang'anyo Onyango \\ Lecturer, Department of Training, Research and Consultancy, Kenya School of Government, Baringo Campus, Kenya
}

\begin{abstract}
The study set out to analyze the relationship between fishing activities and HIV/AIDS and the impact of the institutional framework in the prevention and management of HIV/AIDS in Mfangano Island. The people of this Island are grappling with one of the most critical concentrations of HIV/AIDS in Kenya. With a near monopoly of fishing as the sole economic activity, the island's population has developed risky social behaviour influenced by fishing activities, especially during high fishing seasons. There is an eminent gap between the acknowledged broad range of institutional framework for the combat of HIV/AIDS and the failure to deal with the problem of the scourge in a comprehensive manner in such a uniquely isolated fishing community. The major rationale is that, for there to be prospects for a more robust preventive and control measures in the management of HIV/AIDS in the fishing community, there is need to improve on the existing institutional framework by decentralizing the obligations of the Constituency AIDS Control Committee (CACC) up to the fishermen's "access point". Consequently, increasing the Beach Management Units' (BMUs') capacity to perform any HIV/AIDS preventive and management tasks will ensure alleviation of the spread of the menace. The broad objective was to investigate factors that have influenced the spread of HIV/AIDS in Mfangano Island and how fishing activities have contributed towards this menace. The specific objectives were: to explore the relationship between fishing activities and HIV/AIDS pandemic in the Island; advance the understanding of the pertinent factors responsible for the spread of HIV/AIDS in the Island; and finally, assess the impact of relevant stakeholders in fishing industry in the prevention and management of HIV/AIDS scourge in the Island. The theory posits the existence of a national institutional framework for prevention and management of HIV/AIDS in Kenya. The framework asserts that there is need for recognition of the importance of community involvement in the continuum of case for persons infected and affected by HIV/AIDS; the grassroots level for the framework being the CACC. The study reviewed secondary data on the extent of HIV/AIDS infection, basing its analysis on Mfangano Island as a case study. Questionnaires and interview schedules were administered to seventy (70) respondents while vital and in-depth information to explore details on how fishing activities impact on the spread of HIV/AIDS in the Island was gathered through five (5) focus group discussions. The study observed that HIV/AIDS preventive strategies are predicated on the general information on factors influencing the spread of HIV/AIDS and structured on the national strategic framework to combat the epidemic. The study underscores the challenges to HIV/AIDS prevention among the fishermen and concludes by recommending areas where further research is needed to enhance effective measures on the same.
\end{abstract}

Key Words: Fishing, HIV, AIDS

\subsection{INTRODUCTION}

HIV/AIDS has become a tragedy of devastating proportions in Kenya. The lives of infected individuals, their families and communities, the industries they work in and the country as a whole have been affected by HIV/AIDS epidemic. The magnitude of the problem of HIV/AIDS scourge is threatening the livelihood of not only people of Mfangano but also Kenya as a nation. The crisis is more severe in Mfangano Island whose sole economic activity is fishing. The impact of fishing activities in relation to the spread of HIV/AIDS pandemic can no longer be ignored. The island's population is not secure, instead perishing while languishing in poverty that has crept into the fishing villages. Widows and orphans form a larger proportion of the people left in these villages, while several homes have remained desolate.

The underlying complex factors influencing the spread of HIV/AIDS and the measures for treatment, prevention and management of HIV/AIDS scourge in the island are increasingly being viewed through the narrow lens of the national institutional framework for prevention and management of HIV/AIDS in Kenya. Exclusively applying the institutional framework to a fairly delineated island with poor infrastructure and lack of reliable access from the main land, Mbita Township, is a real threat to the people's health status, in terms of HIV/AIDS infections.

Efforts should be redirected at improving the link between the fishermen and the institutional framework in order to realize the 


\section{Influence of Fishing Activities on HIV and AIDS Pandemic in Mfangano Island, Kenya}

objectives of the National AIDS Control Council (NACC). There is a gap between the acknowledged broad range of the institutional framework for the combat of HIV/AIDS and the failure to deal with the problem of the scourge in a comprehensive manner in such an isolated and remote area. The study therefore, seeks to unravel the missing link in HIV/AIDS prevention and management in Mfangano Island. The project posed the question: Does disconnected intervention strategies create the conditions that perpetrate HIV/AIDS? The study concerned itself with the question of the fishing fraternity and sought to identify their role in creating, perpetuating or simply failing to address the problem of HIV/AIDS, particularly in reference to Mfangano Island.

\subsection{Background of the Study}

The impact of HIV/AIDS in Africa first became apparent in a fishing village on the Ugandan shores of Lake Victoria in $1982 .{ }^{i}$ However, the prevalence of HIV/AIDS in fishing communities has not been extensively studied or addressed since this time. The vulnerability of fishing communities to HIV/AIDS has been widely overlooked by health organizations. Consequently, they have not received the prevention, care and treatment programmes available, a fact which is having devastating impacts on these communities.

Since 1984 when the first case of HIV/AIDS was identified in Kenya, the policy environment has gone through three broad phases. Between 1984 and 1987, a general sense that HIV/AIDS was not a serious problem for the country prevailed. The period, 1988 to 1991, of more realistic appraisal of HIV/AIDS as a potentially harmful health issue, marked the second phase, though there was still a wide belief that HIV/AIDS was not more serious than other diseases. From 1992 to 1995, the third phase was marked, with some significant changes in Kenya's policy environment. The government released its surveillance data and hosted the first National Conference on HIV/AIDS, and the Ministry of Health declared that HIV/AIDS had become a national crisis. ${ }^{\text {ii }}$

Despite these important developments, a strong need still remains for more aggressive action on HIV/AIDS prevention and care. The existing institutional framework for prevention and management of HIV/AIDS in Kenya does not seem to give much attention to the marginalized fishing communities such as the Mfangano island fisher folk.

With the emergence of booming fishing activities during the period between 1995-2000, Mfangano Island's fisher folk developed risky social behaviours resulting to the desolation of several beaches today due to the prominent fishermen's succumbing to HIV/AIDS- related deaths. The study has concerned itself with the practices of fishermen in order to explore the relationship between fishing activities and HIV/AIDS pandemic in the island so as to suggest the best interventions for prevention and management of the scourge.

\subsection{Statement of the Problem}

This study was aimed at investigating how fishing activities impact on HIV/AIDS pandemic in Mfangano Island. "With local HIV/AIDS prevalence rate estimated at over 30\% (19,000 people impacted), Mfangano Island is struggling to address the impact of one of the most critical concentrations of HIV/AIDS anywhere in the world"iii. Fishing, as an economic activity, has highly contributed to HIV/AIDS pandemic in Mfangano Island: HIV/AIDS - related diseases have claimed many lives in Mfangano Island with most victims being fishermen, resulting in reduced labour supply in the fishing industry which is the sole economic activity in the region. This has impacted negatively on the economic livelihood of the people in these rural households, particularly where widows and orphans lose their breadwinners.

Most of the previously prominent fishermen who thrived during the former high fishing seasons are no more; they succumbed to HIV/AIDS- related deaths after experiencing spells of booming fishing seasons. Some beaches, which were mostly inhabited by the locals like "Nyakweri beach" are today desolate, with the village registering the highest HIV/AIDS' orphans in the island, as reflected by the number of orphans admitted at Gethsemane Garden Christian Centre (GGCC), through an established vetting process.

The people develop risky social behaviour during high fishing seasons when there is booming business in fish. Whereas a lot of money exchanges hands, there is a very poor saving culture among the fishermen who believe that "the more rapidly one gets rid of money earned from a day's catch, the more the catch will be the next day and vice versa." This leads to extravagance in their spending in the local bars and restaurants, with the highest percentage of their expenditure centered on risky sexual relationships.

Moreover, children's welfare has been contravened with high rates of school dropout cases since they have to be involved in child labour in the fishing industry to raise money for their basic needs, hence prematurely terminating their education to be faced with a bleak future in terms of lack of formal or professional employment. Furthermore, widows are forced to be inherited by strangers in the name of "foreign fishermen" whose HIV/AIDS status are not determined or are involved in the, "fish for sex" activity. Their daughters are also married off to persons of similar caliber in a "come we stay" arrangement, while the orphaned boys are married to older "foreign women" who are also widows from mainly, the neighbouring Bondo and Migori Districts (the women do this so that the unsuspecting boys may provide them with cheap labour in their respective fishing boats).

There is also a common practice in most fish-landing beaches whereby one or two women "serve" a number of fishermen who normally stay in a single room ("Abila") as the crew of a given fishing boat. Since these women are usually either widows or divorcees with scanty marital arrangements within the beaches, they have a tendency of looking for the favour of being supplied with fish through having unprotected sex ("fish for sex") with almost all the fishermen in the respective "Abila" in turns (these fishermen normally go fishing at night in shifts). 


\section{Influence of Fishing Activities on HIV and AIDS Pandemic in Mfangano Island, Kenya}

Furthermore, daughters of these women are often assigned by their mothers to represent them in serving the fishermen. In this process, these initially innocent girls (mostly orphans), fall prey to the immoral fishermen (usually comprising of drug addicted men and young boys), leading to early pregnancies, girl child school dropouts, and further HIV/AIDS transmission. These girls later become worse than their mothers in spreading HIV/AIDS among the fishermen and all other stakeholders in the fishing industry.

Moreover, some Beach Management Units' (BMUs) officials have resorted to some risky arrangements which further contribute to the spread of HIV/AIDS among the fishermen; such as insisting that each newly arrived woman - fishmonger is officially allocated a fisherman in the beach to be her "husband" ("Jaboya"), without any consideration for prior VCT (Voluntary Counseling and Testing) exercise!

Therefore, in as much as Kenyan government, through the Ministry of Health, has put several interventions in place to fight the HIV/AIDS menace in the country as a whole, there is also the need to have special consideration on how this scourge could be addressed among the Island's fishing fraternity in particular, since this part of the country contributes a higher percentage of the number of people dying annually from HIV/AIDS - related diseases; Nyanza is ranked highest among Provinces in Kenya, with Suba ranking highest among Districts in the Province while Mfangano Island leads among the Divisions in this District. ${ }^{\text {iv }}$

\subsection{Objectives}

Broadly, the study sought to investigate critically, factors that have influenced the spread of HIV/AIDS pandemic in Mfangano Island and how fishing as an economic activity, has contributed towards this menace.

The specific objectives were as follows:

1. To explore the relationship between fishing activities and HIV/AIDS pandemic in Mfangano Island.

2. To advance the understanding of the pertinent factors responsible for spread of HIV/AIDS in Mfangano Island.

3. To assess the impact of relevant stakeholders in fishing industry in the prevention/control and management of HIV/AIDS scourge in Mfangano Island.

\subsection{Hypotheses}

The study was informed by the following three hypotheses:

1. A boom in fishing activities promotes the upsurge of HIV/AIDS.

2. The upsurge of HIV/AIDS is informed by social behaviour in Mfangano Island.

3. The spread of HIV/AIDS pandemic is due to disconnected intervention strategies

\section{5 justification}

The study sought to examine the relationship between fishing and HIV/AIDS in order to unravel the complex interactions in fishing industry and how they influence the social behaviour of fishermen and the spread of HIV/AIDS scourge in Mfangano Island.

The underlying factors influencing the spread of HIV/AIDS are broadly related to knowledge, attitude and practices of the people. In order to have sustainable measures for prevention/control and management of HIV/AIDS, it is necessary to understand the relationship between fishing and HIV/AIDS. There is need to identify the interactive patterns of fishing activities that perpetrate the spread of HIV/AIDS in Mfangano island. The relationship between fishing activities and HIV/AIDS is under researched; the existing institutional framework for prevention and management of the scourge in Kenya conspicuously ignores the role of the fishing fraternity.

Fishing as an economic activity is an aspect which has been neglected in the combat of HIV/AIDS epidemic, despite the fact that HIV/AIDS is wiping out the island's fishing population at an alarming rate which if not addressed promptly, will soon see this beautiful island desolated, as is already evidently eminent in some fishing villages.

\subsection{Scope and Limitations}

The main focus of the study concerned how fishing activities are related to HIV/AIDS pandemic in Mfangano Island. Therefore, the study did not look at the whole issues of HIV/AIDS but only those related to fishing activities, which have a bearing on the social behaviour of the island's fishers.

Furthermore, whereas several other smaller islands with intensive fishing activities surround the island, the study concentrated more on the main island and a relatively closer Takawiri Island.

These aspects of the scope were necessitated by two factors as follows:

1. Convenience; mostly in accessibility, which would have had otherwise, much implication on time and financial requirement for research.

2. The sampled islands are the only ones that inhabit resident local (native) fishermen, unlike the others that may exhibit more booming fish business due to the complex fishing activities there. However, they only inhabit immigrant fishermen, some of whom may be natives of the two islands while a majority of them come from as far as the neighbouring countries of Uganda and Tanzania.

The latter factor explains why there would be no accurate response (from these immigrant fishermen) when collecting data on the trend of fishing activities as related to the spread of HIV/AIDS, an issue they would not have the capacity to vividly comment on, owing to the fact that their presence in the islands is seasonal and thus, they would be biased by basing their observations only on the time they are usually available. 


\section{Influence of Fishing Activities on HIV and AIDS Pandemic in Mfangano Island, Kenya}

\subsection{Theoretical Framework}

This study was undertaken within the institutional framework for prevention and management of HIV/AIDS in Kenya as outlined below:

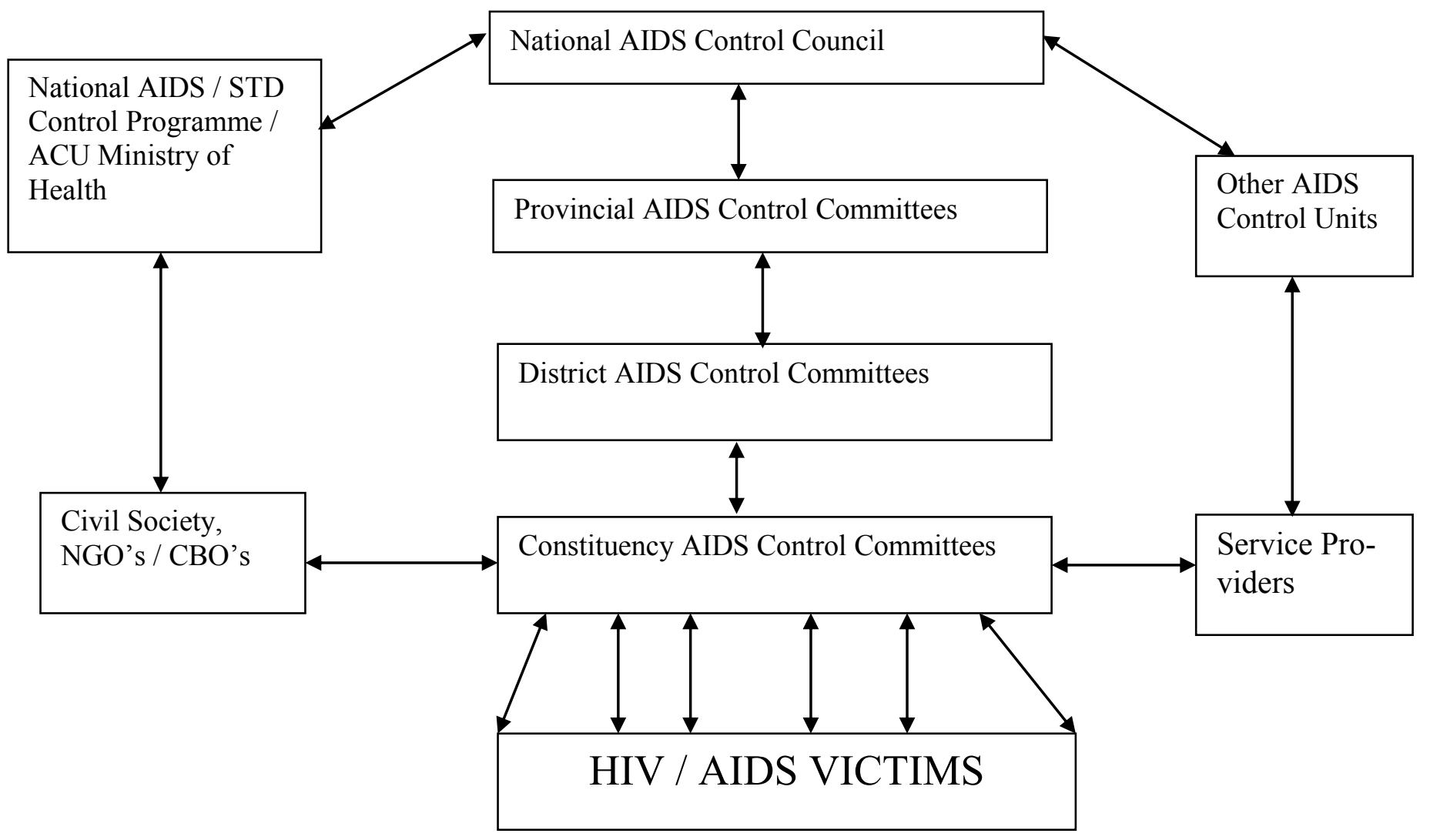

According to the Home-Based orientation package 2003, the Policy Framework for Home-Based Care (HBC) incorporates Policy documents going back to 1985, Sessional paper number 4 of 1997 on AIDS in Kenya and Kenya National HIV/AIDS Strategic Plan 2001-2005; all these recognize the importance of community involvement in the continuum of case for persons infected and affected by HIV/AIDS.

The Strategic Framework to Combat the HIV/AIDS epidemic illustrates how, to meet the challenge of HIV/AIDS in the country, the Government of Kenya approved, in September 1997, Sessional Paper number 4 on AIDS in Kenya (Ministry of Health, 1997). This was a clear intent of the government to support effective programmes to control the spread of AIDS, to protect the human rights of those with HIV or AIDS and to provide care for those infected and affected by HIV/AIDS. The goal of the sessional paper was to "provide a policy framework within which AIDS prevention and control efforts would be undertaken for the next 15 years and beyond." Specifically, it has the following objectives:

1. Give direction on how to handle controversial issues while taking into account prevailing circumstances and the sociocultural environment.

2. Enable the government to play the leadership role in AIDS prevention and control activities. Challenges posed by AIDS call for a multi-sectoral approach, necessitating involvement from a diversity of actors.

3. Recommend an appropriate institutional framework for effective management and coordination of HIV/AIDS programme activities.

The sessional paper recognized that responding effectively to the HIV/AIDS crisis will require a strong political commitment at the highest level; implementation of a multi-sectoral prevention and control strategy with priority focus on young people; mobilization of resources for financing HIV prevention, care and support; and establishment of a National AIDS Control Council (NACC) to promote leadership at the highest level possible. ${ }^{\mathrm{vi}}$

However, it is possible to define a well-documented gap between the existing national super-structures for policy formulation and national programme implementation, supported in many cases by multi- and bilateral agencies, on one side- and the reality at the grassroots level in the local communities on the other. Many of the HIV/AIDS related prevention and control efforts, generated at the national and constituency levels, fail to reach the local community where the needs are most pronounced. And if such efforts do reach out to the local community- they are not always sufficiently socio-economic and cultural-specific and appropriate in order to alleviate the plight of the local population or affect its behaviour, where which may be needed. ${ }^{\mathrm{vii}}$ 


\section{Influence of Fishing Activities on HIV and AIDS Pandemic in Mfangano Island, Kenya}

Nevertheless, a wide range of new Non-Governmental Organizations (NGOs) have been formed in direct response to the epidemic and serve the local communities in highly prioritized and often less glamorous areas such as appropriate HBC and other support for People Living With AIDS (PLWAS) and their families, especially the orphans. Recognizing these facts, many agencies and organizations have increasingly paid attention to and supported NGO-activities in relation to HIV/AIDS. Currently, there is a tendency towards allocation of increasing proportions of national and international resources for HIV/AIDS prevention and control to NGOs. Although there seems to be an elaborate national framework for HIV/AIDS prevention and control, Mfangano Island's fishing community has since been ignored. The institutional framework for prevention and management of HIV/AIDS in Kenya has put in place Constituency AIDS Control Committees (CACC) as the grassroots agency in fighting the epidemic, yet the composition of the constituencies' population varies widely in terms of their respective socio-economic activities. For instance, Mfangano Island is uniquely separated from the rest of Mbita constituency especially, by its geographical position and a near monopoly of fishing as the sole economic activity in the area.

Therefore, it is worthwhile to consider decentralizing the obligations of the CACC in Mbita Constituency up to the fisherman's "access point" in the form of fishermen societies, unions, or BMUs; which should in turn create an HIV/AIDS department directly reporting to the CACC.

\subsection{LITERATURE REVIEW}

Literature review was largely organized around three major themes as follows: the extent of the problem of HIV/AIDS scourge, factors influencing the spread of HIV/AIDS, and measures for treatment, prevention/control, and management of HIV/AIDS.

\subsection{The Extent of the Problem of Hiv/Aids Scourge:}

Despite the fact that other disasters, like floods and wars kill many people, the worst killer today is the AIDS epidemic. It does not discriminate, but targets every class of people. Nevertheless, its intensity varies significantly from one region to the other, for instance, Kakai and Kakai viii state that, out of a population of 6 billion people living in the world, 42 million have so far been infected by HIV/AIDS. Out of these, two thirds or 28 million people are in Africa, out of which 2.5 million are in Kenya.

Piot, Bartos et'al ${ }^{\mathrm{ix}}$, assert that established new HIV infections in 2000 in Sub-Saharan Africa numbered 3.8 million, a similar number to those infected in 1999. This total aggregates different situations across the region in some districts and countries, the epidemic continues to grow strongly whereas in others the epidemic is long-standing and has already reached numbers of people whose behaviour exposes them to HIV/AIDS, leaving a smaller pool of people who can still be infected.

Kakai and Kakai ${ }^{\mathrm{x}}$, further state that the greatest HIV burden is in Sub-Saharan Africa, home to 15 countries with the highest prevalence in the world. In most other regions, HIV infections have been concentrated in various high -risk population. Soskolne $(2000)^{\mathrm{xi}}$ states that the global HIV/AIDS prevalence rates are particularly high in fishing communities, for example $15 \%$ compared to the national average of $0.6 \%$ in Thailand.

Furthermore, Ainsworth and Semai (2000) ${ }^{\text {xi }}$ assert that in Tanzania fishers are estimated to be five times more likely to die of HIV/AIDS - related illnesses than farmers, while Seemangal ${ }^{\text {xiii }}$ asserts that the HIV/AIDS prevalence rates in lakeshore towns(like Homa Bay) is $70 \%$ compared to the national average of $15 \%$ in Kenya. Chassalmen ${ }^{\mathrm{xiv}}$ argues that, with local HIV prevalence estimated at over 30\% (19,000 people impacted), Mfangano island is struggling to address the impact of one of the most critical concentrations of HIV/AIDS anywhere in the world.

\subsection{Factors Influencing the Spread of Hiv/Aids:}

There are 3 modes of transmission of HIVAIDS. Salmen ${ }^{\mathrm{xv}}$ emphasizes that in Kenya, and Mfangano island in particular, sexual transmission; unprotected sexual intercourse (vaginal, oral, and anal) with infected person, is the most common mode. Secondly, contact with blood or other body fluids; transfusion of blood products from an infected person/donor, use of contaminated instruments such as needles, syringes, knives, or blades (including instruments used in circumcision of both males and females, skin piercing scarification, traditional healing and other traditional practices). Thirdly, from an infected mother to a child in the womb, during labour, or with breastfeeding.

Forsythe $^{\mathrm{xvi}}$ recognizes the fact that young men and women are vulnerable to HIV/AIDS infections because they begin sexual activity at an increasingly younger age, tend to have multiple partners and have restricted access to information on safer sexual practices. In addition, the interplay of a wide range of factors - war and instability, the loss in appeal in agriculture as a profession, economic hardship and the absence of income- generating opportunities, the increase in school drop-out rates and alcohol/drug abuse - have contributed to the creation of high risk environment for the rural youth.

Kakai $^{\text {xvii }}$ attributes the spread of HIV/AIDS to lack of fear of the LORD according to the Bible in the book of Proverbs 1:7, however, he contends that not only medical factors are influencing the spread of HIV/AIDS. There are many other contributing factors, first is ignorance; which implies lack of proper information and knowledge about HIV/AIDS and how it is spread, thus causing rumours and misunderstandings. There is a gap between what people know they should do and what they actually do. They ignore facts and expose themselves to great risks. The great problem is how to get people to change and behave in a more responsible way. 


\section{Influence of Fishing Activities on HIV and AIDS Pandemic in Mfangano Island, Kenya}

Secondly, there is social pressure on youth to be sexually explicit. Moreover, lack of moral values often leads to risky sexual behaviour, for instance, under the influence of alcohol and drugs people may indulge in casual sex and get infected. Thirdly, gender irregularity depicts women as often made vulnerable by men's greater economic and social power and by unequal gender relations. In some societies, women cannot exercise their right to refuse a sexual relationship or to claim the use of condoms. Furthermore, widow inheritance is a custom that has become dangerous because of HIV / AIDS, with some African societies upholding the tradition that widows have to be married to their brothers- in-law regardless of their HIV status.

Fourthly, poverty forces men all over Africa to migrate to towns and cities away from their wives and families and engage in temporary/casual jobs, with others traveling much for their work hence, fall into high risk sexual behaviour. Fifthly, vulnerable groups such as desperate people being forced to sell themselves to earn a living, for example, the case for women without support, younger people without income and orphans for whom this is the only way to survive. Adults can also exploit children/youth for sex work to gain profits, thus the younger people forced to work as sex slaves in many poor countries run the risk of getting infected with HIV.

Sixthly, people in power can rob others through political and economic structures; hence, through injustice and greed they rob other people's future and prosperity causing poverty which in turn can lead to illness. Furthermore, there is the Rich Contra Poverty; where the rich countries of the world have sometimes robbed poor countries by taking advantage through high interest loans and self-serving investment. One actual example relating to HIV/AIDS is the fight with some pharmaceutical companies that they want to take advantage through potent laws to keep prices high on essential drugs. Fife and Wright ${ }^{\text {viii }}$ however, summarize these factors as Knowledge, Attitude and Practices (KAP) while discussing Youth and HIV, Youth and Condoms, and high-risk environment for youths.

Moreover, Gellier R. et'al (2004) ${ }^{\mathrm{xix}}$ note the fact that immigrant fishers returning to their home villages after becoming unable to continue with fishing activities, accounts for the reason why fishing communities may not be viewed as having higher prevalence rates of HIV/AIDS. Allison and Seeley (2004) ${ }^{\mathrm{xx}}$ observe that factors that place fishing communities 'among the highest riskgroups in countries with high overall rates of HIV/AIDS prevalence' are; the characteristics of mobility, access to daily cash income, availability of commercial sex, risk-taking, hyper-masculinity and women's subordinate economic and social position.

Karukuza and Bob ${ }^{\mathrm{xxi}}$ assert that poor facilities, over dependence and high level of mobility accompanied by little social cohesion in fishing communities increase the likelihood of the communities engaging in risky behaviour. Most fishing communities are geographically, socially, politically and economically marginalized. They have limited access to HIV/AIDS prevention, care and mitigation strategies. These factors create substantial and critical difference between knowledge and practice with regard to HIV/AIDS in the fishing communities.

They further observe that consumption of alcohol is high among the fishers who mainly work at night and are redundant during the day with the major recreational activities being either drinking or sex. Beer selling is the main source of income of most women in the fishing communities who are readily available customers due to the nature of fishing activities. Moreover, the beer sellers double as commercial sex workers and hence, the fishers (mostly casual labourers) are attracted to them mainly for sexual relations.

\subsection{Measures for Treatment, Prevention/Control and Management of Hiv/Aids:}

Winker concurs with UNESCO in regarding prevention as the best protection. They argue that, since a cure for HIV/AIDS has not yet been found, preventing people from being infected is the most important role of HIV and AIDS Education. Although some very strong drugs are being used to slow down the virus, they don't work for everybody, and are very expensive.

We must all therefore be knowledgeable about the behaviour and conditions which increase the risk of infection, especially in relation to sexual behaviour and intravenous drug use. We may wish to encourage children to abstain from having sexual intercourse as the most reliable method of preventing interaction. If, however, our children do choose to be sexually active it is essential that they use a condom correctly - every time they have sex. The practice of "safe sex" prevents contact with the blood, sperm or vaginal fluids of an HIV - infected person during sexual intercourse. We must be sure that they are well aware of the responsibilities that go along with an active sexual life.

In the same way, by providing accurate information about drug use and its dangers, we would hope to discourage drug abuse in the first place. We may point out that under the influence of drugs (or alcohol), people may be more likely to act irresponsibly forcing sexual behaviours on unwilling partners, or forgetting to use a condom for example. If, however, people choose to use drugs (or use other instruments, such as those used for piercing, tattoos or circumcision), it must be stressed that they should never share or use needles or other instruments which have been used already and not been properly sterilized.

Winker ${ }^{x i i}$ further, emphasizes on being faithful to one partner, having all blood used in transfusions checked for HIV, and making right/good decisions. We need some guidance which should help us make right decisions. The best guidelines are God's Commandments. They are given to guide and protect us, our families, neighbours and friends. They make a guard against evil and enable us to live better lives according to God's way. Finally, this study concurs with the Kenya AIDS Watch Institute (KAWI) who organized the Mbagathi Conference, where participants made their recommendations on the best way to tackle the HIV/AIDS menace in society as follows: 


\section{Influence of Fishing Activities on HIV and AIDS Pandemic in Mfangano Island, Kenya}

\subsubsection{Advocacy and Prevention;}

On this recommendation, they noted that first there is need to revisit and understand the African cultural value system and help propagate the HIV/AIDS facts to each community using their specific cultural value system. Secondly, media should repackage HIV/AIDS information for dissemination, that is, instead of inundating the public with horror and dry facts, analyze critically the socio-economic, cultural, political and demographic implications of HIV/AIDS data, and make it user-friendly.

Thirdly, no particular approach is any longer necessary and sufficient to use nationally. Due to Kenya's different cultural origins, certain messages based on specific cultural backgrounds have more impact hence more useful than generic messages routinely used. Finally, reporting of HIV/AIDS should be mandatory and routine as a step to destigmatize HIV/AIDS infected people. Confidentiality will forever complicate and perpetuate the epidemic.

\subsubsection{Treatment of HIV/AIDS, Care and Support of the Infected and Affected;}

This recommendation proposed the need to amend the Hippocratic oath to allow doctors to disclose their patient's serostatus and that, counseling services should be tailored to suit individual psychological preparedness. Furthermore, HIV/AIDS patients should be encouraged to form post-test clubs where they can meet to share ideas and encourage each other while the pharmaceutical industries should be streamlined.

Moreover, referral centres from the provincial hospital level down the dispensaries at the local level should be included in the VCT package to ensure minimal care for those who test positive and require medical attention. It further suggested profilement of the patient before prescribing ARVs and that, special units dealing with HIV positive patients only should be set up within the hospitals. Finally, training should be carried out on logistics of administering of ARVs and possibly have radio programmes aired at the most appropriate time to prescribe how ARVs should be used.

\subsubsection{Mitigation of Social and Economic Impact of HIV/AIDS;}

On this recommendation they noted the need to first, introduce and intensify community evangelical campaigns through revivals and spiritual counseling by religious leaders. Secondly, train school teachers and parents through the PTAs to handle adolescent sexuality issues with confidence.

Thirdly, mitigation of socio-economic impact of HIV/AIDS should include poverty reduction measures. Fourthly, the Kenyan public should observe strict moral codes borrowing a leaf from Islamic states such a Saudi Arabia, Iran Iraq among others who have a near zero HIV/AIDS incidence. Finally, link VCT to home-based care and support services at community level.

\subsubsection{Information, Monitoring, Evaluation and Research;}

They noted here that NACC ought to move fast in collecting baseline data and inventory of resources being currently used in prevention and control activities. This would make monitoring, evaluation, management and coordination of intervention programmes easier and streamline national efforts towards the war. Furthermore, more behavioural research needs to be undertaken to inform HIV/AIDS IEC development and there is further, the need for continued updating of the HIV/AIDS data/statistics to keep up with the changing epidemiology of the epidemic instead of replaying data that is obsolete.

Moreover, a media research institute should be formed where journalists in need of information on HIV/AIDS can carry out research. Further, duplication of similar HIV/AIDS communication programmes should be avoided and instead, design programmes that will have an impact on the intended target groups and that will bring about change of behaviour. Moreover, areas of interest on the target group, such as Internet for the youth, should be used. Finally, package the information in a way that is appropriate to the audience. Presentation of ideas should take into account the background and prejudices of targeted audiences.

\subsubsection{Management and Coordination;}

Here they noted that NACC should make the strategic plan available to all stakeholders and that national guideline of HIV/AIDS programme management and coordination should be prepared and circulated to all stakeholders. Furthermore, youth and children definitions should be made clear and their representation ensured at the NACC decision-making organs and that, there is need for accountability and transparency in the management of funds channeled toward HIV/AIDS activities.

Moreover, NACC needs to liaise with other organizations and seek the involvement of people in different professions. Further, they noted that bureaucracy and corruption need to be dealt with as they hinder effective response and that, HIV positive persons should be accorded rights similar to those of persons with disabilities.

Furthermore, there is need to declare a state of emergency; criminalize deliberate HIV/AIDS infection of others and amend section 186 of the penal code to make the offence a felony rather than a misdemeanor; carry out preventive diagnosis of all those joining secondary schools, colleges, universities, the disciplined forces and corrective institutions; devote 3\% of VAT collection to finance programme on HIV/AIDS management; enhance capacity building at all levels including setting up of resource centres at the grassroots; and incorporate HIV/AIDS in other development matters.

\subsubsection{HIV/AIDS Policy, Legislation and Human Rights Development;}

This recommendation proposed the provision for National "Census" on preventive diagnosis every 4 years for all those aged 14 years and above (funded by the AIDS levy). Furthermore, the Kenyan public should observe strict moral codes, whereas the government should facilitate the provision of nutritious food supply to the infected and by mainstreaming gender into HIV/AIDS action, priorities be given to women by engaging AIDS widows in creative ventures. 


\section{Influence of Fishing Activities on HIV and AIDS Pandemic in Mfangano Island, Kenya}

Krantz and Staugard, xxiii assert that a multitude of organized prevention and control efforts have been planned and implemented at the national, district and community level in third world countries ever since the HIV/AIDS epidemic became visible there. However, recently, it has become painfully apparent that those organized efforts and the development of a super- and infra-structure for HIV/AIDS prevention and control has only to a limited extent become effective at the grassroots leveling terms of changing attitudes and behavioral modes of members of the average population. Problems have become particularly evident in the area of care, counseling, and social support for PLWAS and their relatives at the local community level.

A well-defined gap can now be documented between the national structure for HIV/AIDS prevention and control on one side- and the tangible problems, facing the most vulnerable groups of population particularly in the sparsely populated and remote areas of many third world countries on the other. Consequently our interests and efforts should be focused on the development of innovative, socio-economic and culture specific strategies for health promotion, counseling, care and social support in the local communities which are now suffering from devastating impact of the AIDS epidemic. ${ }^{\text {xiv }}$

Furthermore, there is the well-established, but not officially recognized, traditional health care structure and numerous THPs who could act as key figures is such gap-filling strategy. Other actors who may be capable of bridging this gap are such as the women and youth groups. Moreover, special emphasis should be put on TBAs as they are key-figures in the informal women's and girls' networks in many societies and may access these networks with relevant, culture-specific information in relation to sexual behaviour and HIV/AIDS. In their role as informal community leaders and guardians of social norms and rules, TBAs could be trained to channel educational messages to the local population on HIV/AIDS issues. ${ }^{\mathrm{xxv}}$

Cambers ${ }^{x x v i}$ observes that in the prioritized list of issues common to all sampled islands in the Caribbean, Indian ocean and Pacific regions;

Health care (insufficient public health facilities, mental health, health care services, HIV/AIDS) rank high. Chassalmen ${ }^{\mathrm{xxvii}}$ notes that, while there are many health organizations in Suba District, the remoteness of Mfangano Island makes it a real challenge to scale-up health infrastructure. There is an immediate need to promote HIV counseling and testing, and support services for people living with HIV/AIDS.

Furthermore, there is some relevancy with Chassalmen's assertion that the remoteness of Mfangano Island makes it a real challenge to scale-up health infrastructure. ${ }^{\text {xxviii }}$ There is need therefore, for potential investors in health organizations to target this Island in specific without dealing with the HIV/AIDS pandemic in Suba District in general. There is further need to recognize the role of Traditional Health Practitioners (THPs) in primary health care by, involving and incorporating them in the institutional framework for prevention and management of HIV/AIDS in Kenya.

On the current policy climate Forsythe and Rau ${ }^{x x i x}$ note that there is no single path by which policy issues will be illuminated and resolved. The pressure of events will be strongest impetus, but structures exist for managing policy development around HIV/AIDS. For instance, the Kenya HIV/AIDS NGOs consortium is using its networks to raise, debate and analyze policy issues; the business community is taking a more active role in policy discussions about HIV/AIDS on the work place and, religious organizations are debating issues that reflect the impact of HIV/AIDS on the lives of their followers.

They further assert that, some of the tools available to policy makers and policy influencers to prevent and mitigate the impact of HIV/AIDS in Kenya is the continued important role played by economic impact assessments of HIV/AIDS epidemic in identifying areas of particular concern and need, thereby providing guidelines in the planning process and assisting in the development of policy responses; the reviews of impact on women, children and businesses, being examples of the priority areas and; the discussions on legal and religious dimensions of the epidemic which outline options for action.

Gullier R. et al (2004) ${ }^{\mathrm{xxx}}$ note the ongoing marginalization of fishing communities from HIV/AIDS interventions, whereby none of the available HIV/AIDS support services fully focus on fishing communities and further, they observe that the recent Fisheries Policy and BMU legislation is silent on HIV/AIDS.

Moreover, Karukuza and Bob ${ }^{\mathrm{xxi}}$ state that, there are few institutional campaign mechanisms put in place to scale down the prevalence and incidence rates of HIV/AIDS among the fishing communities. However, despite the limited access to interventions, the level of knowledge of HIV/AIDS is high, courtesy of the local media services.

Kakai and Kakai ${ }^{\text {xxii }}$ assert that, to maximize the effectiveness of HIV/AIDS programs, the quality of services should be evaluated, and the success of the interventions should be assessed by analyzing trends in morbidity, mortality, and behaviours of populations infected with HIV/AIDS or at risk for HIV/AIDS infection. Using these data to modify and improve HIV/AIDS programs, an approach integrating prevention and treatment is being developed that could reduce treatment need by as much as $50 \%$ by 2020.Furthermore put in place is the government framework for fighting HIV/AIDS running from NACC up to the CACC. ${ }^{\text {xxiii }}$

\subsection{Critical Review of Literature}

The major challenge facing the fishing fraternity in Lake Victoria region in general and Mfangano Island in particular derives mainly from the problem of HIV/AIDS. However, discussing issues pertaining to the extent at which HIV/AIDS has infected the people, factors influencing the spread of HIV/AIDS, and measures for treatment, prevention /control and management of HIV/AIDS is often problematic and requires a critical analysis of the situation in each fishing village (fish-landing beaches).

All literature seems to agree on the fact that HIV/AIDS prevalence rates are high in the sub-Saharan African region with most 


\section{Influence of Fishing Activities on HIV and AIDS Pandemic in Mfangano Island, Kenya}

concentrations of the infections being observed along the lake region among the fishing communities. Gullier R. et al (2004) ${ }^{\mathrm{xxiv}}$ take into account the fact that the influx of immigrant fishermen into the fishing beaches contributes to the high ranking of the fishing communities mostly in terms of prevalence rates of HIV/AIDS. In Mfangano Island most of these "foreign fishermen" have broken the local tradition by indiscriminately inheriting widows to victims of HIV/AIDS-related deaths and actually settling at the local villages despite of their deteriorated health.

This study concurs with Allison and Seeley (2004) ${ }^{\mathrm{xxxv}}$ in identifying the fishing activities that place fishing communities among the highest risk groups in countries with high overall rates of HIV/AIDS prevalence" Even though Karukuza and Bob ${ }^{\mathrm{xxxv}}$ recognize the fact that most fishing communities are marginalized, they ignore the fact that the same fisher folk develop poor spending habits due to easy money or "quick money." With poor saving culture, the fishers are vulnerable to poor living standards such as the poor facilities and over dependence.

Both Gullier ${ }^{\text {xxxvi }}$ and Karukuza, ${ }^{\text {xxxiii }}$ recognize the ongoing marginalization of fishing communities from HIV/AIDS interventions which is in agreement with this study's intent to verify if the spread of HIV/AIDS pandemics due to disconnected intervention strategies. What is missing in literature is a systematic analysis of a case study instead of generalizing the problem of HIV/AIDS in the country (Kenya) or at most, in the rural areas without specific reference to the fishing community in the Island.

Fishing as a socio- economic activity, matters as a major factor influencing the spread of HIV/AIDS, given the extent at which HIV/AIDS has infected and affected the Mfangano Island fishing population. It is nevertheless interesting to investigate the realities both nationality and regionally to see whether there is any entry - point for addressing HIV/AIDS pandemic in the Island through effecting relevant measures for treatment, prevention/control and management of the HIV/AIDS menace by the existing Government Framework for fighting HIV/AIDS.

Despite the acknowledged view that the spread of HIV/AIDS is attributed to Knowledge, Attitude and Practice (KAP), the central linking factor among the Mfangano Island fishing fraternity, is fishing as an economic activity (during the low and high fishing seasons). Evidently, the literature highlights issues that have a bearing on the extent at which HIV/AIDS has infected the people, factors influencing the spread of HIV/AIDS and measures for treatment, prevention/control and management of HIV/AIDS.

Whereas knowledge about HIV/AIDS, Attitude towards HIV/AIDS and Practices of the people, greatly influence the spread of HIV/AIDS, there is need to specifically highlight the role of fishermen and the fishing industry stakeholders, and tie up all issues that have wider ramifications on HIV/AIDS scourge. There is need to comprehend to what extent does the irresponsible social behaviors of the fisher folk contribute to the perpetration of HIV/AIDS in the Lake region and the specific socio- economic implications of the fishing activity that significantly impact on HIV/AIDS.

Even though Kakai and Kakai ${ }^{x x x i x}$ and Piot, et'al ${ }^{x l}$ recognize the fact that the greatest HIV burden is in Sub-Saharan Africa, with the highest percentage of HIV/AIDS infections being in Kenya, they both ignore the obvious fact that this situation is attributed to fishing as an economic activity in the Islands of Lake Victoria, of which Mfangano is the largest on the Kenyan portion of the Lake. However, Kakai and Kakai xli assert that the serologic documentation of AIDS is about the East African population around Lake Victoria bordered by Kenya, Tanzania and Uganda. Chassalmen ${ }^{x l i i}$ is overwhelmed by the local HIV prevalence rate in Mfangano Island; however he has not looked at the main factor behind this alarming data, which this study considers to be fishing as an economic activity in the Island.

Forsythe ${ }^{x l i i}$ argues that the loss in appeal in agriculture as a profession is among a wide range of factors influencing the spread of HIV/AIDS without stating the alternative venture into the "quick-money" fishing industry which has resulted in the neglect of agriculture by the youth. Economic hardship and the absence of income-generating opportunities may not necessarily contribute to the creation of high risk environment for the rural youth, but rather the opposite situation is likely to facilitate the male youths into risky lavish behaviour, with the exception of the females.

He further argues that the increase in school drop-out rates and alcohol/drugs abuse are other such factors, but does not critically look into the circumstances resulting to such status; since, with the "quick-money" from fishing activity the fishermen tend to lure young school girls into unprotected sex, impregnating and infecting them with HIV hence, increase in school drop-out rates. The fishermen have also developed a bogus myth that, "taking alcohol/drugs scare away evil spirits which hover on the lake at night and also, that this keeps them warm and alert in the cold and desolate nights when fishing; this practice done repeatedly, develops into a habit, hence drug abuse and addiction, exposing the fishermen to risky sexual behaviour.

Kakai and Kakai ${ }^{\text {xiv }}$ have not considered how gender irregularity may depict women differently in the fishing community, contrary to the argument that it depicts women as often vulnerable to men's greater economic and social power. In the fish-landing beaches some women, especially the "foreign-women" from neighbouring Districts, own fishing boats and large scale fish business (from their deceased husbands' estate claims), thus lure young boys into sexual relationships. Moreover, widow inheritance in the context of the fisher folk does not necessarily require the compulsory involvement of her in-laws, but rather any "foreign fisherman", which further complicates the issue of knowledge of their HIV/AIDS status.

Whereas Winker ${ }^{x l v}$ states that poverty forces men all over Africa to migrate to towns and cities, with others traveling much for their work hence, fall into high risk sexual behaviour, in Mfangano Island the scenario is a bit complex. Poverty is experienced during low fishing seasons or "closure seasons" yet this is when the inhabitants of the fishing villages live very quiet and disci- 


\section{Influence of Fishing Activities on HIV and AIDS Pandemic in Mfangano Island, Kenya}

plined life. Most established fishermen, who are mostly foreigners, travel back to their native homes while some of the casual labourers in the industry remain behind penniless and desperate for any available menial work in the villages. However, the poverty stricken women in the villages are prone to HIV/AIDS during the high fishing seasons.

On considering measures for treatment, prevention/control and management of HIV/AIDS, evidently the literature emphasizes prevention from infection as the most important role of HIV and AIDS Education. However, there is need to specify fishing as an economic activity which creates conditions that increase the risk of infection, and therefore, rank high the fishing fraternity in the campaign for imparting knowledge about the behaviour and conditions which increase the risk of infection, especially in relation to sexual behaviour.

Furthermore, it is interesting to note that in the Mbagathi Conference, organized by KAWI, the participants' recommendations on the best way to tackle the HIV/AIDS menace in society did not recognize fishing activity and the fisher folk as worthy of being involved in the fight against HIV/AIDS. For instance, in their recommendation on Mitigation of social and Economic impact of HIV/AIDS, they recommended school teachers and parents for training through the PTAs to handle adolescent sexuality issues with confidence, whereas it would be appropriate to also train the fishermen and fishmongers through the BMUs to be able to handle issues of sexual behaviour among the fisher folk with much professionalism.

Moreover, the government framework for fighting HIV/AIDS as outlined only has in place the CACC as the grassroots agency in fighting the epidemic, yet the composition of constituents varies widely in terms of their respective socio-economic activities. For instance, Mfangano Island is uniquely separated from the rest of Mbita Constituency especially, by its geographical position and a near monopoly of fishing as the sole economic activity in the area. Therefore, it is worthwhile to consider decentralizing the obligations of the CACC in Mbita Constituency to the fisherman's "access point" in the form of fishermen societies, unions or the BMUs (which should create an HIV/AIDS department directly reporting to the CACC).

Moreover, Krantz and Staugard, while addressing the issue of identifying the missing links in HIV/AIDS prevention and control, note the problems, challenges, and opportunities in HIV/AIDS prevention and control but ignore the need to single out the fishing community as "the most vulnerable group of the population particularly in the sparsely populated and remote areas of many third world countries"xlvi which they could actually have been referring to.

Even though Forysthe and Rau ${ }^{\text {xlvii }}$ note that structures exist for managing policy development of HIV/AIDS in Kenya and that, the pressure of events will be the strongest impetus, it is hard to infer why they excluded the significance of fishing activities as one of the main contributors to this pressure. Moreover, they do not identify the fishing villages/beaches as one area of particular concern and need. Whereas they argue that the business community is taking a more active role in policy discussions about HIV/AIDS in the work place, they seem to ignore the fish mongers who are actually more vulnerable to HIV/AIDS infections while socially interacting with fishermen whose general social behaviour include risky sexual behaviour in the prevailing fishing beach environment.

Finally, although the literature recognizes the role of THPs, especially the TBAs, for their potential role in health related and community support activities; the women and youth groups should also consist of members from the beaches who are directly involved in fishing activities, so as to be disseminate the healthy living ideas to their colleagues in the fishing industry.

\subsection{RESEARCH METHODOLOGY}

The research design constituted the research plan, structure and strategy or techniques of inquiry into research questions and also included the categories and selection of the sample. The methodology described the sample and sampling procedures, research instruments, data collection procedures and data analysis procedures.

\subsection{Research Design}

The purposes of a case study, of Mfangano island, was to analyze the governmental intervention and institutional and administrative structure, in the treatment, prevention and management of HIV/AIDS and how these strategies impact on the spread of HIV/AIDS in the island.

The data for the study was gathered from three categories of the sample. The first category consisted of people who are directly involved in the fishing industry activities such as the fishermen (the casual labourers), fish mongers, BMU officials and the fishing boat owners (employers in the industry). Second category, was the other fishing industry stakeholders such as owners of various businesses within the beaches, class teachers of the school going orphans from schools neighbouring the beaches, orphaned children, their HIV/AIDS infected/affected guardians, members of households fostering HIV/AIDS orphans, organizations that have recently emerged in the response to the problem of orphans, and the community leaders including the provincial administrators. The third additional category was the medical practitioners from government institutions, NGOs, Community Based Organizations (CBOs), private clinics, TBAs, HIV/AIDS counselors and the THPs.

\subsection{Description of the sample and sampling procedures}

The study relied on quota sampling method to obtain data and pertinent information with respect to fishing activities and HIV/AIDS. The sampling frame was drawn from five of the eighteen beaches in Mfangano Island and the respective adjacent 


\section{Influence of Fishing Activities on HIV and AIDS Pandemic in Mfangano Island, Kenya}

villages, taking into account their average population, which is estimated at one hundred and two hundred people per beach and the adjacent villages respectively.

The targeted sample was therefore thirty and sixty people from each of the five beaches and villages respectively. The only health centre in the island was sampled to represent the other four government health facilities, while one private clinic was sampled out of the four administrative locations of the island. The researcher further sampled five schools out of the eighteen schools along the lake shore, near the respective fishing beaches.

\subsection{Description of the data collection instruments}

The study was approached from various perspectives whereby vital and in- depth information to explore details on how fishing activities impact on the spread of HIV/AIDS in Mfangano island was gathered through five focus group discussions with the stakeholders in the fishing industry, complemented by data from documentary sources and research surveys. Thirty questionnaires were administered to fishermen, stakeholders in fishing industry and resource persons from the teaching profession, health practitioners and local leaders.

Factual information and data was sought through documentary research on the prevailing HIV/AIDS situation in relation to fishing activities in Mfangano Island. This information reinforced the information captured through other research instruments. Further focus group discussions and interviews were conducted with experts working with organizations dealing with HIV/AIDS in the island. The focus group discussions with key informants were concentrated on their interactions and experiences with the governmental institutions on the prevention and management of HIV/AIDS.

In- depth interviews for those residing within the selected beaches and adjacent villages were conducted and informal interviews done to verify the capacity of the governments' institutional framework to combat the spread of HIV/AIDS pandemic and authenticate factors influencing the spread of HIV/AIDS in the island. These interviews were deemed necessary for enriching the findings of the study by describing the cultural milieu in which the changes and subsequent adjustments to HIV/AIDS related deaths occur.

In-depth interview schedules for HIV/AIDS- affected parents, orphans and their caretakers were administered to twenty respondents. The guiding questions were:

1) How many people are affected by HIV/AIDS?

2) Relationship between fishing activities and HIV/AIDS.

3) Government interventions and their effectiveness.

4) People's understanding of, and involvement in, government's institutional framework for prevention and management of HIV/AIDS.

\subsection{Data Collection procedure}

In order to establish the relationship between fishing activities and HIV/AIDS in Mfangano Island, it was necessary to first check health facilities' and assistant chiefs' held death registers to determine the occupation of deceased persons from these records. The information was then corroborated with HIV/AIDS counselors in the other organizations dealing with HIV/AIDS and the Orphans and Vulnerable Children (OVC) projects in the island.

Interviews were conducted during both the high fishing seasons (in the third and fourth weeks of every month) with a boom in fishing activities and during the low fishing seasons (in the first and second weeks of every month), so as to establish the varying social behaviours which impact on the upsurge of HIV/AIDS in the island. However, due to the current food situation in Kenya, the government lifted the ban in fishing during the usual closure period of between the months of April and August, which normally present real situation of the low fishing season.

In order to avoid ethical problems, the local HIV/AIDS counselors were used as research assistants to administer the interview schedules to HIV/AIDS victims whom they are actually familiar with. Questionnaires and probing lists were prepared to be selfadministered so as to explore the social context of HIV/AIDS, treatment of the victims, the relationship between fishing activities and HIV/AIDS and how stakeholders in the fishing industry and the government are involved in the prevention and management of HIV/AIDS in the island.

\subsection{Data Analysis Procedures}

In order to classify and hence, compare different pieces of information to draw conclusions and translate information that would be collected, the study analyzed the data by use of the various data processing methods such as the descriptive, critical and statistical analyses all combined together. The data from different methods was commingled and critically analyzed to discern interactions and impact of factors influencing the spread of HIV/AIDS in the island.

Based on the data, the study attempted to identify possible governmental institutions which have impacted on the spread of HIV/AIDS. It examined to what extent these institutions addressed HIV/AIDS pandemic in relation to fishing activities. 


\section{Influence of Fishing Activities on HIV and AIDS Pandemic in Mfangano Island, Kenya}

\subsection{DATA PRESENTATION, ANALYSIS AND DISCUSSION OF THE FINDINGS}

The study drew findings on the extent of HIV/AIDS infection in Mfangano Island, fishing activities as a major contributing factor to the phenomenon of the spread of HIV/AIDS in the Island, and, fishermen's understanding of, and involvement in the government's institutional framework for prevention and management of HIV/AIDS.

\subsection{The Extent of HIV/AIDS Infection in Mfangano Island}

The researcher sought for the District AIDS and STI Coordinator's (DASCO's) VCT data for the year 2008, from the only Health Centre on the Island and from one of the private clinics. This was as displayed in the following Table A:

Table A: Number of people tested for HIV/AIDS in Mfangano Island

\begin{tabular}{|l|l|l|l|l|}
\hline Name of Health Facility & \multicolumn{3}{l|}{} & \multicolumn{2}{l|}{ St. Luke Clinic } \\
\hline Month & $\begin{array}{l}\text { Number ona Health Centre } \\
\text { people Tested }\end{array}$ & $\begin{array}{l}\text { Number of people } \\
\text { Tested Positive }\end{array}$ & $\begin{array}{l}\text { Number of } \\
\text { people Tested }\end{array}$ & $\begin{array}{l}\text { Number of people Tested } \\
\text { Positive }\end{array}$ \\
\hline January & 40 & 11 & 16 & 03 \\
\hline February & 27 & 09 & 49 & 18 \\
\hline March & 44 & 18 & 32 & 09 \\
\hline April & 31 & 15 & 41 & 16 \\
\hline May & 77 & 17 & 20 & 07 \\
\hline June & 66 & 16 & 14 & 04 \\
\hline July & 81 & 15 & 37 & 15 \\
\hline August & 52 & 13 & 25 & 09 \\
\hline September & 40 & 11 & 30 & 12 \\
\hline October & 31 & 05 & 18 & 08 \\
\hline November & 16 & 03 & 46 & 11 \\
\hline December & 24 & 04 & 34 & 12 \\
\hline TOTALS & $\mathbf{5 2 9}$ & $\mathbf{1 3 7}$ & $\mathbf{3 6 2}$ & $\mathbf{1 2 4}$ \\
\hline
\end{tabular}

4.1.1 Computing Statistic for Table A

$$
\begin{gathered}
\text { HIV/AIDS prevalence rate: } \\
\left(\frac{\text { Total number of people Tested positive }}{\text { Total number of people Tested }}\right) \times 100
\end{gathered}
$$

Therefore, HIV/AIDS prevalence rate of people tested at Sena Health Centre in the year, 2008;

$$
\begin{gathered}
=(137 / 529 \times 100) \% \\
=\underline{\underline{25.90} \%}
\end{gathered}
$$

While, HIV/AIDS prevalence rate of people tested at St. Luke Clinic in the year, 2008;

$$
\begin{aligned}
& =(124 / 362 \times 100) \% \\
& =\underline{\underline{34.25}} \%
\end{aligned}
$$

Hence, the average local HIV/AIDS prevalence rate for the people who were counseled and tested in the year, 2008;

$$
\begin{aligned}
& =\underline{(25.90+34.25)} \\
2 & =\underline{\underline{\mathbf{3 0 . 0 8}} \%}
\end{aligned}
$$

\subsubsection{Interpretation and Discussion of the Results and Findings}

With local HIV/AIDS prevalence rate estimated at over $30 \%$ among the 653 people counseled and tested in the year 2008, Mfangano Island is struggling to address the impact of one of the most critical concentrations of HIV/AIDS anywhere in Kenya. Comparatively, Kenya's HIV/AIDS prevalence rate is estimated at $7.5 \%$, while Nyanza Province is rated at $14 \%$ whereas Suba District is rated at $26 \%$.

4.2 Fishing Activities as a major contributing Factor to the phenomenon of the spread of HIV/AIDS in Mfangano Island Seventy (70) respondents (fishing stakeholders) were interviewed to ascertain the relationship between fishing activities and the spread of HIV/AIDS in Mfangano island. The results are tabled in Table B as follows: 
Influence of Fishing Activities on HIV and AIDS Pandemic in Mfangano Island, Kenya

Table B: Fishing Activities' contribution to the spread of HIV/AIDS

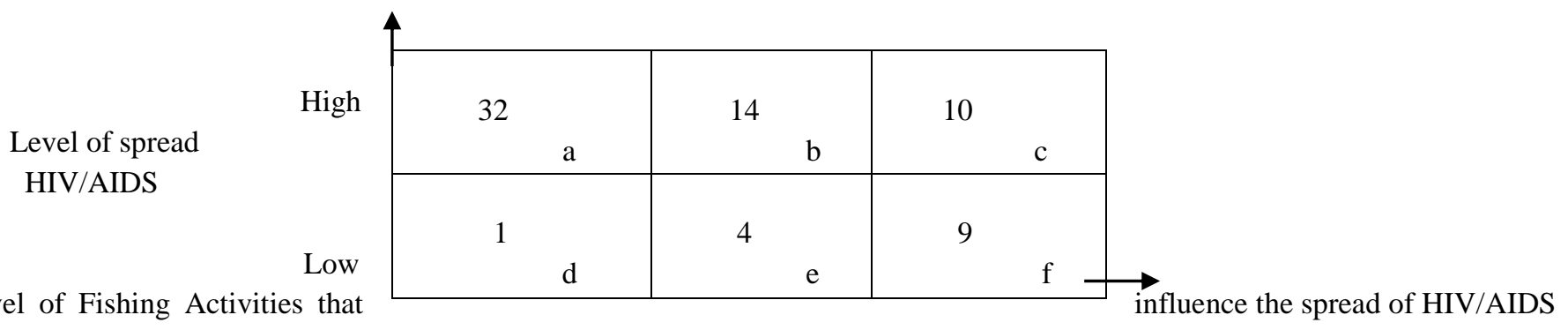

\subsubsection{Computing Statistic for Table B}

Formula for Gamma (r):

$$
r=\frac{(A \times D)-(B \times C)}{(A \times D)+(B \times C)}
$$

Where; $\mathrm{AD}=$ Frequency of the Agreement, and

$\mathrm{BC}=$ Frequency of the Disagreement.

Therefore; $\mathrm{AD}=[32 \times(4+9)+(14 \times 9)]=542$

$\mathrm{BC}=[10 \times(4+1)+(14 \times 1)]=66$

Hence, the Score $=(542-66)$

$$
\begin{gathered}
(542+66) \\
=\underline{\underline{+0.8}}
\end{gathered}
$$

\subsubsection{Interpretation and Discussion of the Results and Findings}

There actually exists a relationship between the level of the spread of HIV/AIDS and Fishing Activities in Mfangano Island. The nature of the relationship is a positive one and its strength rated as strong.

Therefore, with reference to the study's objective to explore the relationship between fishing activities and HIV/AIDS pandemic in Mfangano Island, the results of the findings imply that there is a strong agreement with the assumption (hypothesis) that fishing activities is a major contributing factor to the phenomenon of the spread of HIV/AIDS in the Island.

4.3 Fishermen's Understanding of, and Involvement in Government's Institutional Framework for the Prevention and Management of HIV/AIDS.

The study sought to find out whether three categories of respondents agreed among themselves to the fishermen's understanding of, and involvement in the government's institutional framework for the prevention and management of HIV/AIDS in Mfangano Island. The statistics were tabulated in Table C:

Table C: Fishermen's understanding and involvement in Government's institutional framework for the prevention and management of HIV/AIDS

\begin{tabular}{|l|l|l|l|l|l|l|l|}
\hline $\begin{array}{l}\text { Name of } \\
\text { Beach }\end{array}$ & $\begin{array}{l}\text { Category 1: } \\
\text { BMU Offi- } \\
\text { cials }\end{array}$ & $\begin{array}{l}\text { Category 2: } \\
\text { Fishermen } \\
(\text { Casuals })\end{array}$ & $\begin{array}{l}\text { Category 3: } \\
\text { Medical } \\
\text { Practitioners }\end{array}$ & $\begin{array}{l}\text { Total } \\
\text { Score } \\
(\mathbf{X})\end{array}$ & $\begin{array}{l}\text { Mean } \\
(\overline{\mathbf{X}})\end{array}$ & $\begin{array}{l}\text { Deviation } \\
(\mathbf{d}) \\
(\mathbf{X}-\overline{\mathbf{X}})\end{array}$ & $(\mathbf{X}-\bar{X})^{\mathbf{2}}$ \\
\hline Nyakweri & 2 & 3 & 6 & 11 & 14 & -3 & 9 \\
\hline Mrongo & 7 & 6 & 4 & 17 & 14 & +3 & 9 \\
\hline Sena & 4 & 7 & 6 & 14 & 14 & 0 & 0 \\
\hline Takawiri & 3 & 5 & 5 & 14 & 14 & 0 & 0 \\
\hline Ugina & 6 & 3 & 5 & 14 & 14 & 0 & 0 \\
\hline
\end{tabular}

\subsubsection{Computing Statistic for Table C:}

Kendall formula:

$$
\mathrm{W}=\frac{\mathrm{S}}{1 / 12} \frac{\underline{\mathrm{K}^{2}\left(\mathrm{~N}^{3}-\mathrm{N}\right)}}{\mathrm{K}}
$$


Where;

$\mathrm{S}=$ Sum of the squares of the observed deviations from the mean.

$\mathrm{K}=$ The number of sets of rankings (Units being ranked).

$\mathrm{N}=$ Number of cases being observed.

Therefore;

$$
\begin{gathered}
\mathrm{S}=18, \mathrm{~K}=3 \text { and } \mathrm{N}=5 . \\
\mathrm{W}=\frac{\text { Hence; }}{1 / 12} \underset{\mathrm{X} 3^{2}\left(5^{3}-5\right)}{18} \\
=\underline{\underline{\mathbf{+ 0 . 2}}}
\end{gathered}
$$

\subsubsection{Interpretation and Discussion of the Results and Findings}

The three (3) categories of respondents do not highly agree on the fishermen's understanding of, and involvement in the government's institutional framework for the prevention and management of HIV/AIDS in Mfangano Island.

The coefficient of concordance is $\mathbf{+ 0 . 2}$ indicating that there is no much agreement among the respondents regarding the question of fishermen's understanding of, and involvement in the government's institutional framework.

\subsection{SUMMARY OF THE FINDINGS, CONCLUSION AND RECOMMENDATIONS}

This chapter outlines a summary of the whole study from the study's objectives to the findings; Conclusion of the study, based on the findings and the objectives which the researcher set out for the study, and finally; Recommendations that are within the context of the study's findings.

\subsection{Summary}

The impetus of this study emanated from the quest to shift the focus from the narrow perspective of the national institutional framework for prevention and management of HIV/AIDS in Kenya, to the involvement of fishermen in the fight against the spread of HIV/AIDS. This is because the fishermen's organizational structures such as the BMUs are familiar with the fishing activities that relate to HIV/AIDS, and their proximity to the epidemic's theatre enhances layered response to the pandemic.

The study's objectives were to explore the relationship between fishing activities and HIV/AIDS, advance the understanding of the pertinent factors responsible for the spread of HIV/AIDS menace, and assess the impact of relevant stakeholders in the fishing industry in the prevention and management of HIV/AIDS in the Island.

Quota sampling method was used to obtain data and pertinent information with respect to fishing activities and HIV/AIDS. The sampling frame was drawn from five beaches, their respective adjacent villages, the only health centre in the Island and one of the private clinics. A total of seventy (70) respondents were interviewed and five (5) focus group discussions conducted, complimented by data from documentary sources and research surveys.

The study's findings comprised the extent of HIV/AIDS infection in Mfangano Island, which depicted a local HIV/AIDS prevalence rate of 30\%; fishing activities as a major contributing factor to the phenomenon of the spread of HIV/AIDS in the Island and finally; fishermen's understanding of, and involvement in the government's institutional frame work for the prevention and management of HIV/AIDS.

\subsection{Conclusion}

The findings of this study compel the researcher to suggest that there is a strong relationship between fishing activities and HIV/AIDS pandemic in Mfangano Island. Fishing activities is a major contributing factor to the phenomenon of the spread of HIV/AIDS in the Island.

The study seems to indicate that there is a gap between the acknowledged broad range of the institutional framework for the combat of HIV/AIDS and the failure to deal with the problem of the scourge in a comprehensive manner among the fishing community. The national institutional framework seems to have ignored the fishermen's understanding of, and involvement in the prevention and management of HIV/AIDS.

The researcher is further compelled to suggest that Mfangano Island is a major contributor to Suba District's HIV/AIDS prevalence rate ranking. With local HIV/AIDS prevalence rate estimated at over 30\%, Mfangano Island contributes significantly to the District's HIV/AIDS prevalence rate which is estimated at $26 \%$ compared to the country's $7.5 \%$.

\subsection{Recommendations}

The study's findings seem to indicate that there is need to identify the interactive patterns of fishing activities that perpetrate the spread of HIV/AIDS in Mfangano Island's fishing community. Further research is needed to enhance effective measures for the prevention and management of HIV/AIDS among fishermen.

It is hard to infer why the government found it necessary to exclude the fishing community, which is a significant variable, while formulating the national institutional framework for the prevention and management of HIV/AIDS. The strategic framework 


\section{Influence of Fishing Activities on HIV and AIDS Pandemic in Mfangano Island, Kenya}

needs to undergo certain changes so as to unravel the missing link in HIV/AIDS prevention and management among the fisher folk. Decentralizing the obligations of the CACC up to the fishermen's "access point" in such a constituency as Mbita, would consequently increase the BMUs' capacity to perform any HIV/AIDS preventive/control and management tasks to ensure the alleviation of HIV/AIDS pandemic in the Island.

The BMUs' objectives as outlined in the By-Laws Model for BMUs in Kenya are as follows: to strengthen the management of fish-landing stations, fisheries resources and the aquatic environment; to support the sustainable development of the fisheries sector and; to prevent and/or reduce conflicts in the fisheries sector. However, the study recognizes the necessity for the BMUs' objectives to include a strategy for the prevention/control and management of HIV/AIDS at the respective beaches.

Moreover, the By-Laws Model for BMUs in Kenya should include an HIV/AIDS coordinator in the list of office bearers who form the executive committee listed in the section for Election. This beach official would be in-charge of a committee that would be dealing with issues concerning "behaviour change" on matters such as discouraging immoral practices like "fish for sex", living in "abila" where several fishermen are served by one woman. This committee would consequently encourage fishermen to embrace the saving culture, so as to spend their hard earned money wisely, diversify their economy and develop a positive attitude towards VCT.

\section{REFERENCES}

1) Cabrera C., et'al (Eds.). AIDS AND THE GRASSROOTS: Problems, Challenges and Opportunities. Ipelegeng Publishers, May 1996.

2) Cambers.G. SMALL ISLANDS VOICE: Voices in a changing world, UNESCO (2004).

3) Central Bureau of Statistics (CBS) [Kenya], Ministry of Health (MOH) [Kenya], and ORS Macro.2004. Kenya Demographic and Health Survey 2003. Calverton, Maryland: CBS, MOH, and ORS Macro.

4) Chassalmen, The Organic Health Response (OHR) for Mfangano Island; A project submitted on $29^{\text {th }}$ Oct. 2008, at the University of California in San Francisco (UCSF).

5) Fife B.L and Wright E.R, STIGMA: The dimensionality of stigma; a comparison of its Impact on the Self of persons with HIV/AIDS and Cancer.

6) Forysthe S. and Rau B. (eds) (June 1996), AIDS in Kenya; Socio economic impact and policy implications. Family Health International/AIDSCAP (1996).

7) Gullier R. et al (October, 2004), The Impact of HIV/AIDS on Fishing Communities in Uganda, Marine Resources Assessment Group and Options Consultancy Services Ltd.

8) Kakai P.S. and Kakai C.S., HIV/AIDS: How to control it? (4 ${ }^{\text {th }}$ June 2008).

9) Kenya; Haggling over Aid for Aids, Africa Confidential, Vol 34, No.11, May 1993

10) P. Piot, et al., the Global impact of HIV/AIDS, Insight Review Articles (19 $9^{\text {th }}$ April 2001) Macmillan Pub. Ltd. (2001).

11) Republic of Kenya, Ministry of Health, Home Based Care Orientation Package for Health Services Personnel Managers. (2003). Government Printers, Nairobi 2003.

12) Republic of Kenya, Office of Vice President and Ministry of Planning and National Development, Suba District Development Plan 1997 - 2000. Government Printers Nrb.

13) Salmen .C, Micro - Clinics and Organic Farms for HIV + Kenyans. (12th Dec 2008).

14) Staugard F. and Anderson S. Traditional Midwives, Ipelegeng Publishers, Botswana, 1986.

15) The problems caused by HIV/AIDS within fishing communities, (2006) Fisheries: Communication International Development Research. Natural research highlights, June 2006.

16) United Nations Educational, Scientific and Cultural Organizations; an Article of Living and Learning in a World of HIV/AIDS. (2001).

\section{About the author:}

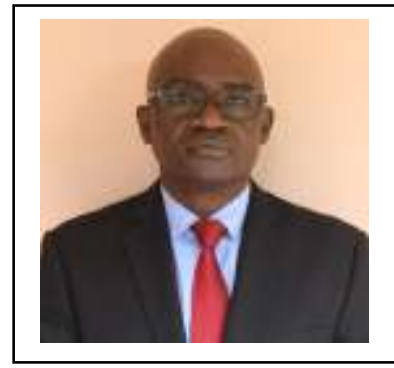

Michael Ang'anyo Onyango is a Lecturer in the Department of Training, Research and Consultancy at Kenya School of Government and a former Assistant Chief in Mfangano Island and Assistant County Commissioner in the Ministry of Interior and Coordination of National Government, Kenya. $\mathrm{He}$ is a Ph.D. candidate in Political Science at Moi University and holds Master of Arts Degree in Public Administration and Policy. His first Degree is B.A. in Political Science and Public Administration. He has Diploma in Public Administration from Moi University and Certificate in Forestry from Kenya Forestry College. He has to his credit a number of publications in reputable books and journals. His research interests are: Governance, Public Administration and Policy, Public Sector Reforms and Performance Management, Effective Leadership and Organizational Change. 


\section{ENDNOTES}

1) i “The problems caused by HIV/AIDS within fishing communities", (2006) Fisheries: Communication

2) International Development Research. Natural Research Highlights June 2006 p1.

3) ii Kenya: Haggling over Aid for Aids, “ Africa Confidential, Vol 34, No.11, May 1993.

4) iii Chassalmen, The Organic Health Response (OHR) for Mfangano Island; A project submitted on $29^{\text {th }}$ October, 2008.

5) iv Republic of Kenya, Office of Vice president and Ministry of Planning and National Development, Suba

6) District Development plan, 1997 - 2000. Nairobi, Government printers.

${ }^{v}$ Central Bureau of Statistics (CBS) [Kenya], Ministry of health (MOH) [Kenya], and ORS Macro. 2004.

Kenya Demographic and Health Survey (2003). Calverton, Maryland: CBS, MOH, and ORS Macro. p5.

${ }^{\mathrm{vi}}$ See note 5.

10) vii Cabrera C., et al, (eds.), AIDS and the GRASSROOTS; Problems, Challenges, and Opportunities. Ipelegeng Publishers (1996). $\mathrm{P}^{7}$

11) viii Kakai P.S. and Kakai C.S., HIV/AIDS, How to control it? (4 ${ }^{\text {th }}$ June 2008) p. 9.

12) ix P. Piot, et'al: Insight Review Articles (19 ${ }^{\text {th }}$ April 2001): The Global impact of HIV/AIDS,

13) Macmillan Magazine Publishers, Ltd (2001).

14) $\quad$ See note 8, p. 39.

15) xi Soskolne (2000), in Gellier R. et al (October, 2004) The impact of HIV/AIDS on Fishing

16) Communities in Uganda, Marine Resources Assessment Group and options Consultancy Services Ltd.

17) p. 21

18) xii See note 11.

19) xiii See note 11.

20) xiv See note 3.

21) xv Salmen.C, Micro - Clinics and Organic Farms for HIV + Kenyans.

22) ${ }^{\mathrm{xvi}}$ Forsythe. S, AIDS in Kenya: Socio - economic impact and policy implication (1996).

23) xvii See note 8, pp. 23-25.

24) xviii Fife B.L and Wright E.R, STIGMA: The dimensionality of stigma; A comparison of its. Impact on

25) the Self of persons with HIV/AIDS and Cancer.

26) xix Gullier R. et'al, (eds.) (October 2004) The Impact of HIV/AIDS on Fishing Communities in Uganda. p. 22.

27) $\quad{ }^{x x}$ See note 19.

28) ${ }^{x x i}$ Karukuza N.W and Bob C.E (2005), Susceptibility and Vulnerability to HIV/AIDS among the

29) Fishing Communities in Uganda: A case study of Lake Kioga; a paper presented at the International

30) Conference on HIV AIDS and Food and Nutrition Security. Durban, South Africa on $14^{\text {th }}-16^{\text {th }}$ April

31) 2005 .

32) xxii Winker. G, "How To Prevent Further Spread" in Kakai R.S. and Kakai C.S., HIV/AIDS, How to control it? (4 June 2008), p. 27.

33) xxiii Krantz G. and Staugard F., in Cabrera C., et al (Eds.) (1996), AIDS AND THE GRASSROOTS:

34) Problems Challenges and Opportunities, p. 3.

35) xxiv See note 25.

36) $\quad{ }^{x x v}$ Anderson S. Staugard F. Traditional Midwives, Ipelegeng Publishers, Botswana, 1986.

37) xxvi Cambers .G., SMALL ISLANDS VOICE: Voices in a changing world, UNESCO (2004).

38) xxvii See note 3.

39) xxviii See note 3.

40) xxix Forysthe S. and Rau B. (eds) (June 1996), AIDS in Kenya; Socio economic impact and policy implications, p. 9-10.

41) $\mathrm{xxx}$ See note 19, p. 22.

42) xxxi See note 21, p. 6.

43) xxxii See note 8, p. 40.

44) xxxiii Republic of Kenya, Ministry of Health, Home Based Care Orientation Package for Health Services Personnel (2003).

45) $\quad$ xxiv See note 19, p. 11.

46) ${ }^{x x x v}$ See note 36.

47) $\quad{ }^{x x x v i}$ See note 21, p. 6.

48) xxxvii See note 19 , p. 11.

49) xxxviii See note 21, p. 6.

50) xxix See note 8, p. 40.

51) ${ }^{x l}$ Piot P. et al, The Global impact of HIV/AIDS, Insight Review Articles (19 ${ }^{\text {th }}$ April 2001). Macmillan Magazine Publishers. Ltd (2001).

52) xli See note 8 , p. 10 .

53) xlii See note 3.

54) xliii See note 29.

55) xliv See note 8, p. 10. 
Influence of Fishing Activities on HIV and AIDS Pandemic in Mfangano Island, Kenya

56) xlv See note 22. p. ${ }^{27}$

57) xlvi See note 7, p. 3.

58) xlvii See note 29, p $9-10$

59) 